\title{
Inhibition of TLR4 inhibits allergic responses in murine allergic rhinitis by regulating the $\mathrm{NF}-\kappa \mathrm{B}$ pathway
}

\author{
HANGYU XU ${ }^{1}$, HAIRONG SHU ${ }^{1}$, JIE ZHU ${ }^{2}$ and JIANXIN SONG ${ }^{1}$ \\ ${ }^{1}$ Department of Otolaryngology; ${ }^{2}$ Medical Test Center, Taizhou Central Hospital, \\ Taizhou University Hospital, Taizhou, Zhejiang 318000, P.R. China
}

Received October 20, 2018; Accepted March 29, 2019

DOI: $10.3892 /$ etm.2019.7631

\begin{abstract}
The present study investigated the underlying mechanisms and effects of toll-like receptor 4 (TLR4) on a mouse model of allergic rhinitis (AR). An ovalbumin (OVA)-induced mouse model of AR was treated with TLR4-short hairpin RNA (shRNA). Allergic symptoms were then subsequently assessed. Protein levels of OVA-specific immunoglobulin E ( $\mathrm{IgE}$ ), eosinophil cation protein (ECP), leukotriene C4 (LTC4) and prostaglandin D2 (PGD2) in mice serum and nasal lavage fluid, as well as various inflammatory cytokine mediators in mice serum, were determined by ELISA. Protein level detection was performed using reverse transcription-quantitative PCR and western blot analysis. The results revealed that TLR4 was highly expressed in the nasal mucosa of AR mice. TLR4 inhibition significantly relieved OVA-induced AR symptoms. Relief of symptoms was evidenced by a decreased frequency of sneezing and nose friction, reduced levels of OVA-specific IgE, ECP, LTC4, PGD2, less inflammatory cells and decreased levels of T-helper 2 type cytokines. In addition, the data indicated that OVA-induced activation of the $\mathrm{NF}-\kappa \mathrm{B}$ pathway was repressed by TLR4-shRNA. The results of the current study indicate that TLR4 may be a promising therapeutic target of AR.
\end{abstract}

\section{Introduction}

Allergic rhinitis (AR) is characterized by the inflammation of the nasal mucosa and is one of the most common chronic diseases in the world, with its prevalence rapidly increasing over the past few decades (1). AR induces inflammation of the upper respiratory tract, which is associated with mediators released by several types of hypersensitive immune cells, including antigen presenting cells, eosinophils, B cells and

Correspondence to: Dr Hangyu Xu, Department of Otolaryngology, Taizhou Central Hospital, Taizhou University Hospital, 999 Donghai Avenue, Taizhou, Zhejiang 318000, P.R. China

E-mail: xuhangyu1810@163.com

Key words: allergic rhinitis, toll-like receptor 4, nuclear factor $\kappa \mathrm{B}$ pathway, allergic response mast cells (2). Many patients with AR often exhibit complications including chronic sinusitis and asthma (3). AR seriously affects the lives of patients as the disease greatly increases the familial and socio-economic burden (4). There are several commonly used AR treatments, including intranasal steroids, antihistamines, leukotriene receptor antagonists and immunotherapy $(5,6)$. However, patients with AR always have unsatisfactory results (7). It is therefore necessary to assess novel and effective AR treatments (8).

Within AR, genetic and environmental factors work in congruence (9). The consensus is that AR is an immunoglobulin $\mathrm{E}$ (IgE)-mediated specific type I hypersensitivity reaction, which is induced by the imbalance of T-helper (Th) 1 and Th2 immune responses in the body, and the nasal mucosal Th2 immune response (10). Regulating the balance of Th1 and Th2 immune responses therefore serve preventive effects on AR. In 1988, Hashimoto et al (11) identified a Toll gene in Drosophila and in 1996, the Toll gene was revealed to serve a role in Drosophila immunity (12). Medzhitov et al (13) then identified toll-like receptors (TLRs) in humans and mammals. TLRs are pattern recognition receptors that serve a very important role in innate and acquired immune responses $(14,15)$. TLRs participate in the innate immune response but also affect the type and intensity of the acquired immune response, stimulate immune cells to synthesize immune factors and regulate the differentiation of T cells (16). Within the TLR family, the most studied is TLR4, which localizes to the cell membrane and the cytoplasm and is assessed primarily in immune cells (17). TLR4 is activated by and recognizes, bacterial lipopolysaccharide (LPS), which is the main molecular component of the cell wall in gram-negative bacteria $(18,19)$. Upon cell membrane receptor dimerization, the TLR4 receptor system initiates a cascade of protein-protein interactions, resulting in the production of pro-inflammatory cytokines and interferons $(17,20)$. These events initiate the inflammation and immune response $(17,20,21)$. When TLR4 binds to its ligand, it induces Th0 cells to differentiate into Th2 cells and therefore promotes the occurrence of Th2-associated allergic diseases (22-24). Therefore, TLR4 may serve an important role in the pathogenesis of AR. A previous study has revealed that TLR4 is highly expressed in the nasal mucosa of patients with AR (25). However, the role of TLR4 in AR remains unclear.

The aim of the current study was to investigate the precise role and molecular mechanism of TLR4 in the mouse model of AR and to explore. 


\section{Materials and methods}

Ovalbumin (OVA)-induced AR establishment. A total of 40, 6-week-old BALB/c mice ( $20 \mathrm{~g} ; 20$ male and 20 female) were obtained from Charles River Laboratories, Inc. Mice were maintained under a $12 \mathrm{~h}$ dark/light cycle, $20 \pm 1^{\circ} \mathrm{C}$ room temperature, and $55 \pm 5 \%$ humidity with free access to food and water. All animal experiments were performed in accordance with the protocol approved by the Care and Use of Laboratory Animals Committee. The current study was approved by the Committee on the Use and Care of Animals of Taizhou Central Hospital (Taizhou University Hospital, Taizhou, China). Mice were randomly divided into four groups $(\mathrm{n}=10)$ : A control group; an AR group; an AR+control-short hairpin RNA (shRNA) group and an AR+TLR4-shRNA group. The AR mouse model was constructed as previously described (26). Briefly, mice were sensitized with an intraperitoneal injection of $25 \mu \mathrm{g}$ OVA and $2 \mathrm{mg}$ aluminum hydroxide (Sigma-Aldrich; Merck KGaA) on days 0,7 and 14 to promote primary sensitization. One week after the last intraperitoneal injection, mice were intranasally challenged with $3 \%$ OVA daily for a week for secondary immunization.

Intranasal administration of TLR4-shRNA. A total of $20 \mu \mathrm{l}$ control-shRNA (cat. no. sc-108080; Santa Cruz Biotechnology, Inc.) or $20 \mu 1$ TLR4-shRNA (cat. no. sc-40261-v; Santa Cruz Biotechnology, Inc.) was intranasally administrated to mice $3 \mathrm{~h}$ prior to every daily OVA challenge (once a day) on days 28-34. AR group mice were treated with $20 \mu \mathrm{l}$ saline $3 \mathrm{~h}$ prior to every daily OVA challenge (once a day) on days 28-34.

Evaluation of nasal symptoms. For $10 \mathrm{~min}$, after the last administration of OVA challenge, the frequency of sneezing and nose friction (scratching of the nose by the mouse) in mice was calculated to assess early allergic reactions.

Inflammation cell counting (27). Inflammation cells (leucocytes, eosinophils, neutrophils and lymphocytes) in the nasal lavage fluid (NLF) were counted. Cells were re-suspended in NLF with $1 \mathrm{ml} 100 \mathrm{mmol} / \mathrm{l} \mathrm{PBS}$ and 1\% BSA (cat. no. ST023; Beyotime Institute of Biotechnology). A hemocytometer (Mindray 3000; Shenzhen Mindray Bio-Medical Electronics Co., Ltd.) was subsequently used to count the number of leucocytes. Wright's-Giemsa staining was then performed at $37^{\circ} \mathrm{C}$ for $20 \mathrm{~min}$ to detect eosinophil, neutrophil and lymphocyte numbers under a light microscope at a magnification, $\mathrm{x} 200$.

ELISA. After the last TLR4-shRNA or control-shRNA administration, the blood and NLF samples of mice were collected. Serum was harvested from blood samples and NLF supernatant was obtained by centrifugation for $10 \mathrm{~min}$ at $1,600 \times \mathrm{g}$ and $4^{\circ} \mathrm{C}$; the samples were then stored at $-80^{\circ} \mathrm{C}$ until use. To determine the protein levels of OVA-specific IgE (cat. no. 439807-1; BioLegend, Inc.), eosinophil cation protein (ECP; cat. no. ABB-KTE71563-48T; Abbkine Scientific Co., Ltd.), leukotriene C4 (LTC4; cat. no. E-EL-M0753km-1; Shanghai Zhenyu Chemical Technology Co., Ltd.) and prostaglandin D2 (PGD2; cat. no. ABB-KTE70766-48T; Abbkine Scientific Co., Ltd.) in the plasma and NLF samples of mice from different groups, ELISA was performed. The secretion of several pro-inflammatory factors and anti-inflammatory factors including interleukin (IL)-4 (cat. no. ab221833), IL-5 (cat. no. ab204523), IL-13 (cat. no. ab219634), IL-17 (cat. no. ab100702), tumor necrosis factor alpha (TNF- $\alpha$; cat. no. ab208348), interferon- $\gamma$ (IFN- $\gamma$; cat. no. ab252352) and IL-2 (cat. no. ab223588; all Abcam) in mice serum were assessed using an ELISA kit according to manufacturer's protocol. Analysis of the ELISA detection limit for each protein revealed that no samples were below the detection limit.

Reverse transcription-quantitative PCR (RT-qPCR). An RNeasy Mini kit (Qiagen, Inc.) was used to extract total RNA from nasal mucosa cells, according to the manufacturer's protocol. The PrimeScript First Strand cDNA Synthesis kit (Takara Biotechnology Co., Ltd.) was utilized for cDNA synthesis as per the manufacturer's protocol. Synthesized cDNAs were analyzed using qPCR with SYBR RT-PCR kit (Takara Bio, Inc.) on the MiniOpticonTM RT PCR System (Bio-Rad Laboratories, Inc.). The amplification conditions were as follows: $98^{\circ} \mathrm{C}$ for $1 \mathrm{~min}$, followed by 40 cycles at $98^{\circ} \mathrm{C}$ for $10 \mathrm{sec}, 56^{\circ} \mathrm{C}$ for $20 \mathrm{sec}$ and $72^{\circ} \mathrm{C}$ for $30 \mathrm{sec}$. Primer sequences were as follows: TLR4, forward 5'-CCTGACACC AGGAAGCTTGAA-3' and reverse 5'-TCTGATCCATGC ATTGGTAGGT-3'; GAPDH, forward 5'-CTTTGGTATCGT GGAAGGACTC-3' and reverse 5'-GTAGAGGCAGGGATG ATGTTCT-3'. Relative gene expression levels were calculated using the $2^{-\triangle \Delta C a}$ method (28). GAPDH was used as the internal control. All experiments were performed in triplicate.

Western blot analysis. Total nasal mucosa proteins were extracted from mice using an M-PER Mammalian Protein Extraction Reagent (ThermoFisher Scientific, Inc.) according to manufacturer's protocol. Protein concentrations were measured via a BCA kit according to manufacturer's protocol. Protein samples ( $30 \mathrm{mg} / \mathrm{lane}$ ) were separated by $10 \%$ SDS-PAGE and subsequently transferred onto PVDF membranes (Merck KGaA). Membranes were blocked in 5\% skim milk at room temperature for $2 \mathrm{~h}$ and then incubated with the following primary antibodies: Phosphorylated (p)-p65 (cat. no. 3033), p65 (cat. no. 8242), TLR4 (cat. no. 14358) and $\beta$-actin (cat. no. 4970; all dilution: 1:1,000; Cell Signaling Technology, Inc.), at $4^{\circ} \mathrm{C}$ overnight. After membranes were washed five times with TBST, they were incubated with a horseradish-peroxidase-conjugated anti-rabbit secondary antibody (cat no. 7074; 1:5,000; Cell Signaling Technology, Inc.) for $1 \mathrm{~h}$ at room temperature. Proteins were detected using SignalFire ${ }^{\mathrm{TM}}$ Plus ECL Reagent (cat. no. 12630; Cell Signaling Technology, Inc.) and imaged. Band density was quantified using Gel-Pro Analyzer densitometry software (version 6.3; Media Cybernetics, Inc.).

Statistical analyses. All experiments were repeated three times. Data were presented as the mean \pm standard deviation. Data analyses were performed using SPSS 18.0 statistical software (SPSS Inc.). A one-way ANOVA, followed by a Tukey's test, was used to measure the significance between groups. $\mathrm{P}<0.05$ was considered to indicate a statistically significant difference. 


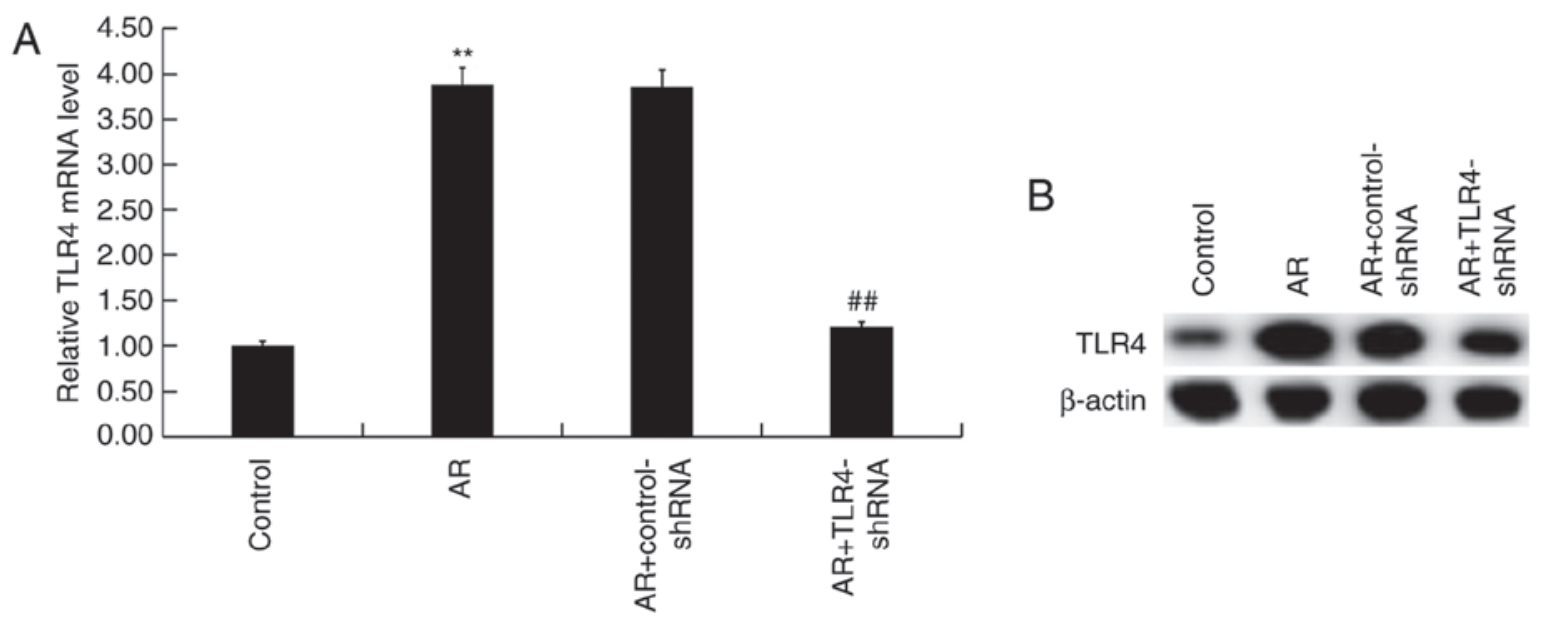

Figure 1. Expression of TLR4 in the nasal mucosa of AR mice. (A) mRNA and (B) protein levels of TLR4 in the nasal mucosa of control, AR, AR+control-shRNA and AR+TLR4-shRNA mice were detected using reverse transcription-quantitative (RT-q) PCR and western blot analysis. Data are presented as the mean \pm standard deviation. ${ }^{* *} \mathrm{P}<0.01$ vs. control group; ${ }^{\# /} \mathrm{P}<0.01$ vs. AR group. TLR4, toll-like receptor 4; AR, allergic rhinitis; mRNA, microRNA; shRNA, short hairpin RNA.
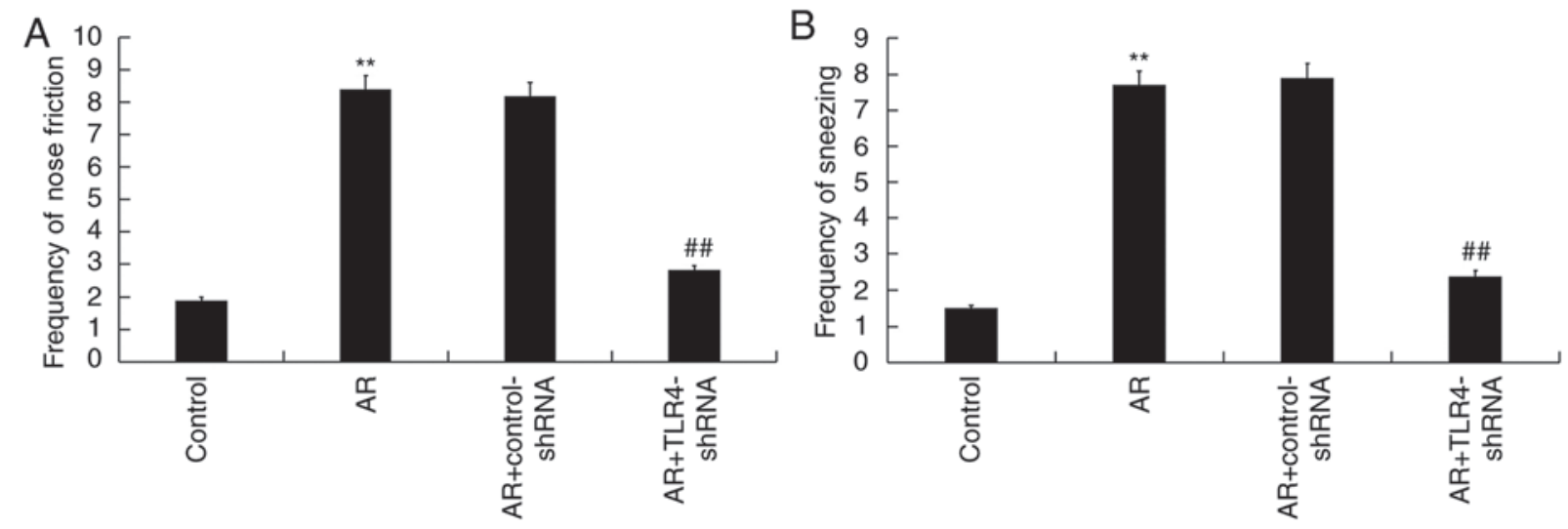

Figure 2. Frequency of (A) rubbing and (B) sneezing was recorded for $10 \mathrm{~min}$ after the last OVA challenge. The number of sneezes or nasal rubs was significantly decreased in the TLR4 inhibition group. Data are presented as mean \pm standard deviation. ${ }^{* *} \mathrm{P}<0.01$ vs. control group; ${ }^{\# \#} \mathrm{P}<0.01$ vs. AR group. OVA, ovalbumin; TLR4, toll-like receptor 4; AR, allergic rhinitis; shRNA, short hairpin RNA.

\section{Results}

TLR4 is upregulated in the nasal mucosa of AR mice. mRNA and protein levels of TLR4 were detected in the nasal mucosa of AR mice using RT-qPCR and western blot analysis. TLR4 mRNA levels were significantly upregulated in AR mice compared with the control group, whereas TLR4-shRNA significantly reduced levels compared with AR mice (Fig. 1A). Similarly, protein levels of TLR4 were markedly upregulated in AR mice compared with the control group, whereas TLR4-shRNA markedly reduced levels compared with the AR group (Fig. 1B).

TLR4 downregulation alleviates AR symptoms in mice. To assess the role of TLR4 in the regulation of AR, TLR4-shRNA was administered into the nostril daily for 7 days, $3 \mathrm{~h}$ before OVA challenge on days 28-34. The frequency of sneezing and nose friction were detected after the last administration of OVA challenge. Compared with the control group, OVA induction significantly increased the frequency of nose friction and sneezing, while TLR4-shRNA administration significantly reduced the frequency of each when compared with the AR group (Fig. 2A and B).

TLR4 downregulation decreases allergic inflammatory cytokine and OVA-specific IgE levels in AR mice. To assess the underlying mechanisms of TLR4-shRNA in AR, levels of allergic inflammatory cytokines and immunoglobulins, including OVA-specific IgE, ECP, LTC4 and PGD2, were determined in the serum and NLF of mice. Enhanced levels of OVA-specific IgE, LTC4 and ECP in the serum of AR mice were reduced by TLR4-shRNA administration (Fig. 3A-C). The upregulated OVA-specific IgE, LTC4 and PGD2 in the NLF of the mice also decreased in the TLR4-shRNA treatment (Fig. 3D-F).

TLR4 downregulation decreases inflammatory cell numbers in the NLF of AR mice. Compared with the control group, the total number of cell leucocytes (Fig. 4A), eosinophils (Fig. 4B), neutrophils (Fig. 4C) and lymphocytes (Fig. 4D) were significantly increased in AR mice, and were markedly reduced by TLR4-shRNA treatment. 

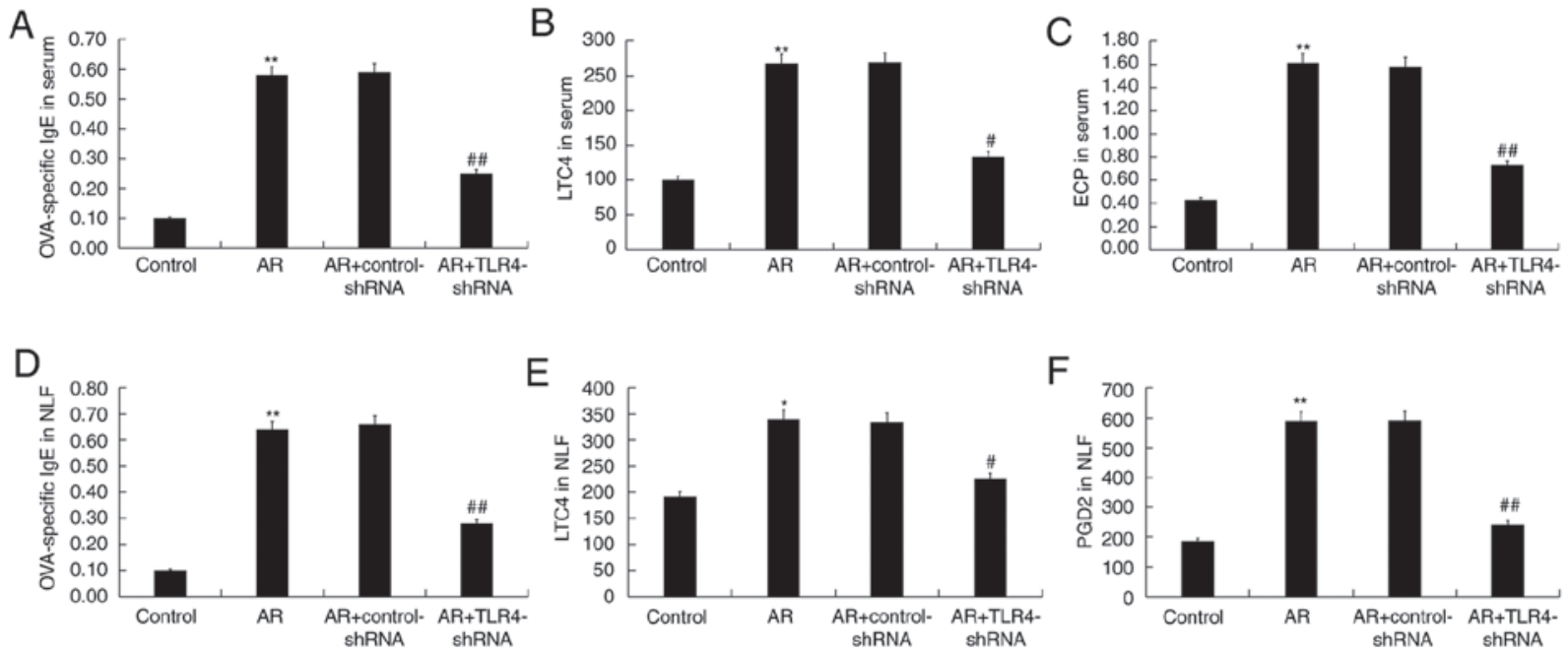

Figure 3. TLR4 inhibition decreased OVA-specific (A) IgE, (B) LTC4 and (C) ECP in serum, and OVA-specific (D) IgE, (E) LTC4 and (F) PGD2 in the NLF of AR mice. Data are presented as the mean \pm standard deviation. ${ }^{*} \mathrm{P}<0.05,{ }^{* *} \mathrm{P}<0.01$ vs. the control group; ${ }^{\#} \mathrm{P}<0.05$, ${ }^{\# \#} \mathrm{P}<0.01$ vs. the AR group. TLR4, toll-like receptor 4; OVA, ovalbumin; IgE, immunoglobulin E; LTC4, leukotriene C4; ECP, eosinophil cation protein; PGD2, prostaglandin D2; NLF, nasal lavage fluid; AR, allergic rhinitis; shRNA, short hairpin RNA.

A
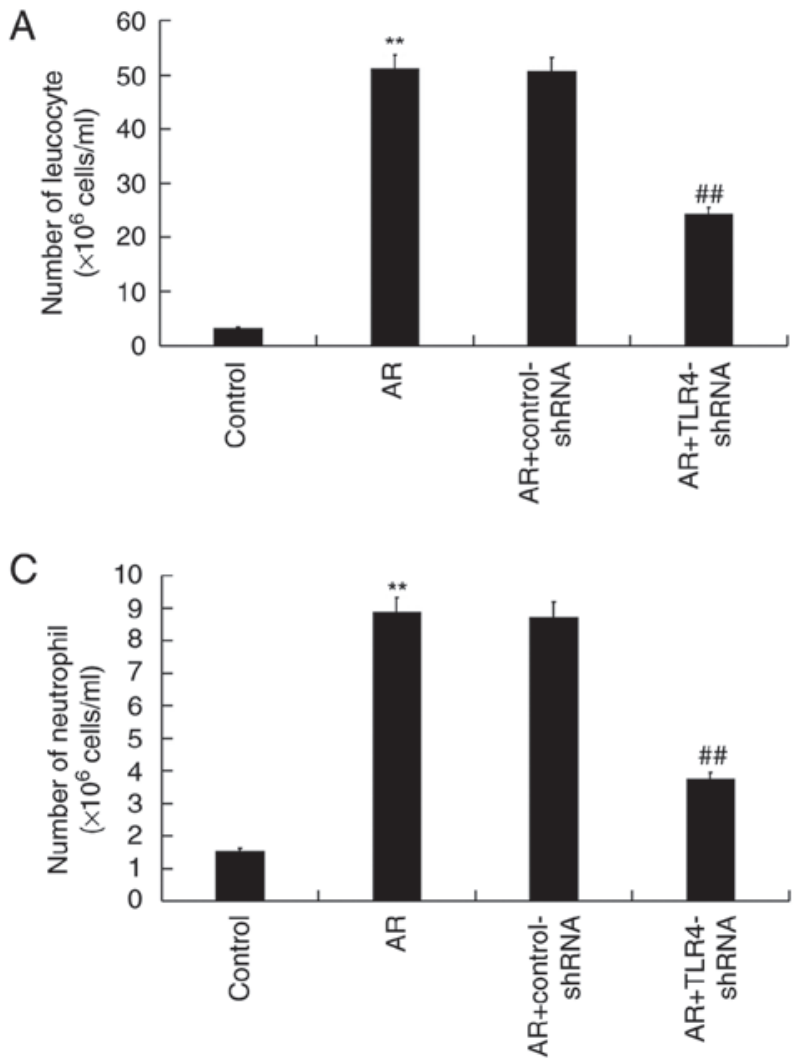

B
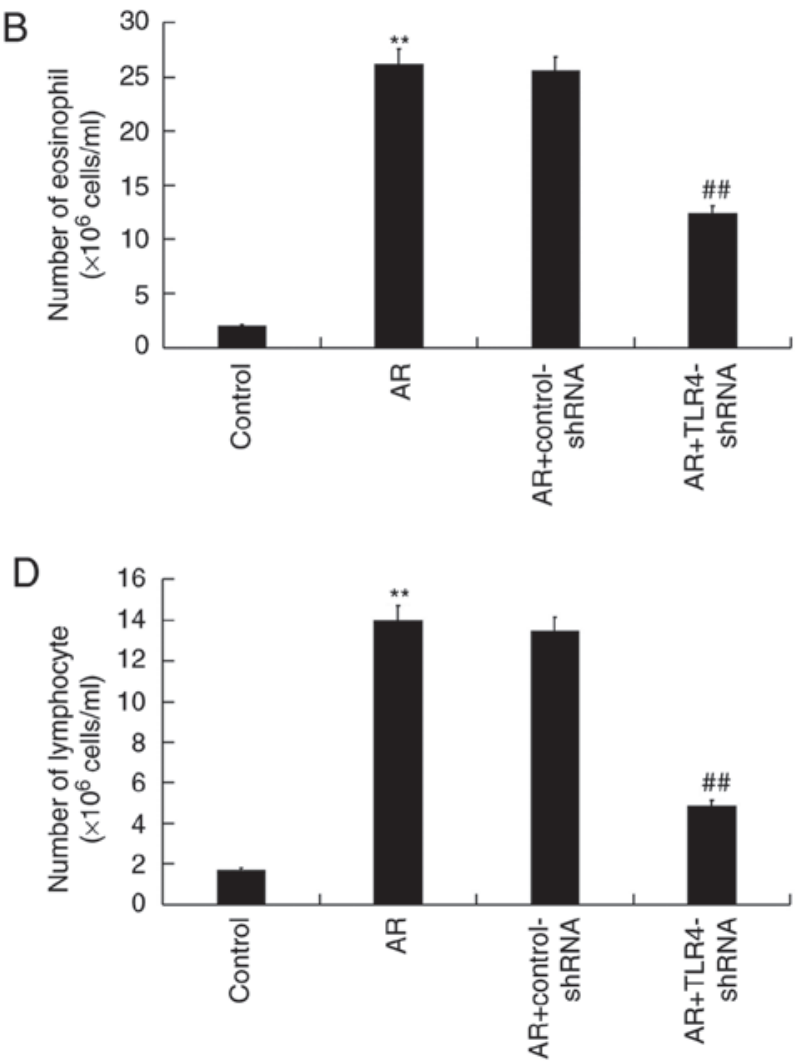

Figure 4. TLR4 inhibition decreased the number of (A) leucocytes, (B) eosinophils, (C) neutrophils and (D) lymphocytes in the NLF of AR mice. Data are presented as the mean \pm standard deviation. ${ }^{* *} \mathrm{P}<0.01$ vs. control group; ${ }^{\# \#} \mathrm{P}<0.01$ vs. AR group. TLR4, toll-like receptor 4; NLF, nasal lavage fluid; AR, allergic rhinitis; shRNA, short hairpin RNA.

TLR4 downregulation affects inflammatory cytokine secretion in the serum of AR mice. Pro-inflammatory factors and anti-inflammatory factors, including IL-4, IL-5, IL-13, IL-17, TNF- $\alpha$, IFN- $\gamma$ and IL-2, in the serum of mice were measured. Compared with control mice, levels of IL-4 (Fig. 5A), IL-5 (Fig. 5B), IL-13 (Fig. 5C), IL-17 (Fig. 5D) and TNF- $\alpha$ (Fig. 5E) in the serum of AR mice significantly increased, while the levels of IFN- $\gamma$ (Fig. 5F) and IL-2 (Fig. 5G) significantly decreased. TLR4-shRNA administration significantly reversed each affect in AR mice.

TLR4 downregulation regulates the activation of the NFKB pathway in the nasal mucosa of AR mice. Whether the NF- $\kappa \mathrm{B}$ pathway was involved in the effects of TLR4 on AR mice was 

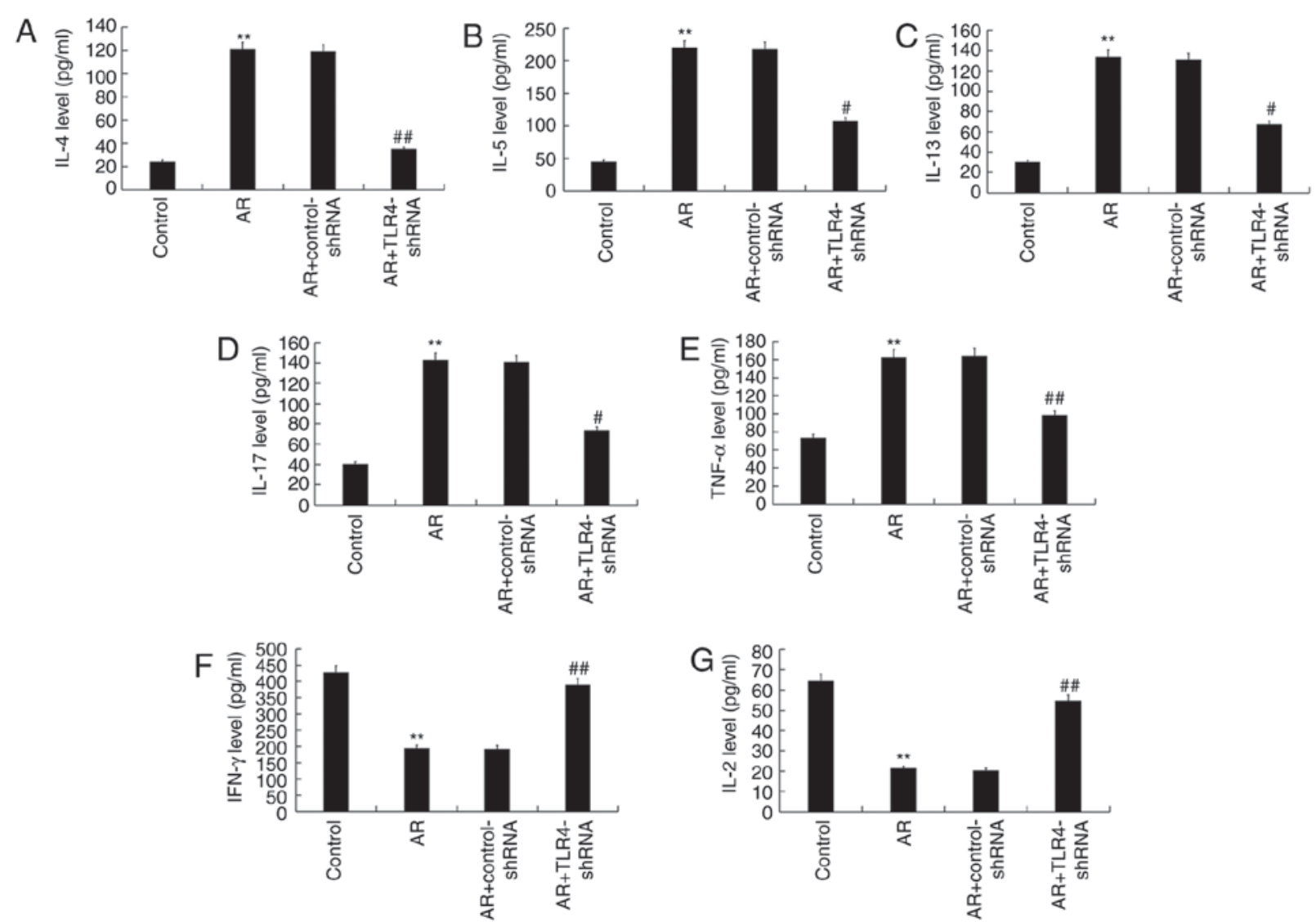

Figure 5. TLR4 inhibition impacted inflammatory cytokine secretion in the serum of AR mice. (A) IL-4, (B) IL-5, (C) IL-13, (D) IL-17, (E) TNF- $\alpha$ (F) IFN- $\gamma$ and (G) IL-2 secretion. Data are presented as the mean \pm standard deviation. ${ }^{* *} \mathrm{P}<0.01$ vs. control group; ${ }^{*} \mathrm{P}<0.05$ and ${ }^{\# \#} \mathrm{P}<0.01$ vs. AR group. TLR4, toll-like receptor 4; AR, allergic rhinitis; IL, interleukin; TNF- $\alpha$, tumor necrosis factor alpha; IFN- $\gamma$, interferon $\gamma$; shRNA, short hairpin RNA.
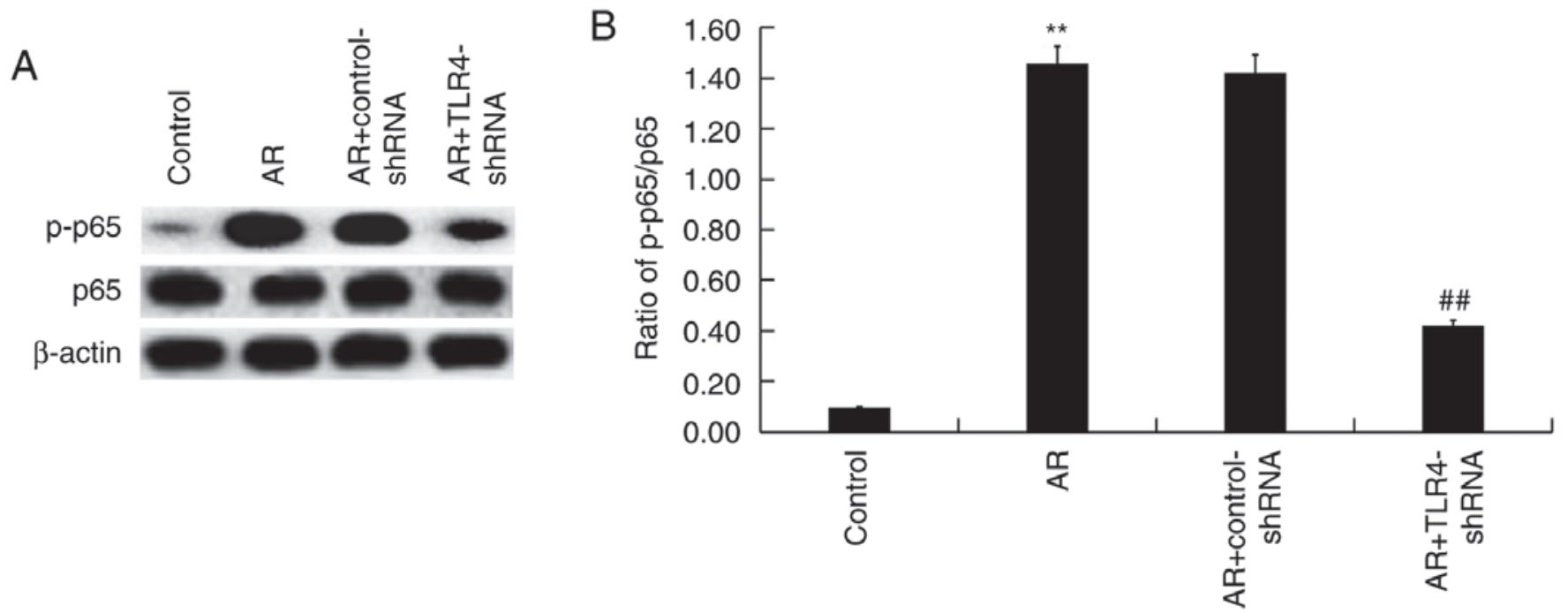

Figure 6. Effect of TLR4 inhibition on the NF-kB pathway in the nasal mucosa of AR mice. Western blot analysis was used to detect (A) p-p65 protein levels as well as (B) the ratio of p-p65/p65. Data are presented as the mean \pm standard deviation. ${ }^{* *} \mathrm{P}<0.01$ vs. control group; ${ }^{\# \#} \mathrm{P}<0.01$ vs. AR group. TLR4, toll-like

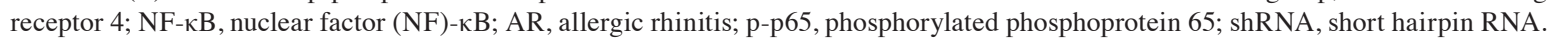

assessed. Protein levels of p-p65 and p65 were determined via western blot analysis (Fig. 6A) and the ratio of p-p65/p65 was calculated and presented in Fig. 6B. The increased protein level of p-p65 observed in AR mice was significantly decreased via TLR4-shRNA administration (Fig. 6B).

\section{Discussion}

The present study demonstrated that TLR4 was upregulated in the nasal mucosa of AR mice. Furthermore, TLR4 inhibition may significantly relieve AR symptoms, as indicated by the 
decreased frequency of sneezing and nose friction, reduced levels of OVA-specific IgE, ECP, LTC4, PGD2, fewer inflammatory cells and decreased levels of Th2 type cytokines. The results demonstrated that the activation of the NF- $\mathrm{KB}$ pathway, induced by OVA, was repressed by TLR4-shRNA administration. Data in the present study also revealed TLR4-shRNA administration exerted a protective effect on AR.

$\mathrm{AR}$ is one of the most common types of rhinitis. Previous epidemiological studies indicate that the average incidence rate of AR is $10-20 \%$ and the annual incidence rate is increasing $(29,30)$. In the past few years, the incidence and severity of AR in developed countries has gradually increased and AR has become a serious public health problem $(4,31)$. Although some progress has been made in the treatment of AR, the therapeutic effect is still unsatisfactory (5-8). Therefore, finding new and effective methods and targets for the treatment of AR is essential.

TLR4, a well-characterized receptor for gram-negative bacterial endotoxins or LPS $(32,33)$, participates in inflammatory signaling responses. TLR4 recognizes ligands including LPS, lipooligosaccharides, bacterial endotoxins and substances secreted by viruses, fungi and mycobacteria by pathogenassocial-edmolecular patterns (34-36). In addition, TLR4 recognizes endogenous ligands including high mobility group box protein 1 and $\beta$-defensin, among the dangerous/damage-associated molecular patterns (36). TLR4 induces a pro-inflammatory immune response by recognizing pathogens and endogenous ligands, but abnormal expression can also promote the occurrence of various diseases (37). Cui et al (25) reported that TLR4 is highly expressed in the nasal mucosa of patients with AR. Various studies have also alluded to the critical roles of TLR4 in the development of AR $(38,39)$. However, the precise role of TLR4 in AR progression remains largely unclear. Therefore, the current study was performed.

In the current study, an OVA-induced AR mouse model was established and treated with TLR4-shRNA. Consistent with a previous study (25), the results demonstrate that mRNA and protein levels of TLR4 in the nasal mucosa of AR mice were significantly upregulated in comparison with control mice. TLR4-shRNA administration markedly reduced the frequency of sneezing and nose friction in AR mice, suggesting that symptoms were alleviated. During the pathogenesis of AR, an allergen triggers a Th2-predominant immune response that produces antigen-specific IgE which bind to mast cells (40). Repeated exposure to the same allergen activates IgE-binding mast cells, which release inflammatory mediators including histamine and leukotriene C4 (41). These promote the initial irritation and sneeze reflex of mice (42). ECP is the most widely used marker for monitoring diseases involving eosinophils (43). PGD2 is critical in the interaction between different immune cells including mast cells, Th2 cells, eosinophils and dendritic cells (44). Consistent with a previous study, levels of OVA-specific IgE, ECP, LTC4 and PGD2 in AR mice significantly increased (27). The present study indicated that TLR4-shRNA administration markedly decreased the levels of OVA-specific IgE, ECP, LTC4 and PGD2 in AR mice. Consistent with these results, the results of the current study also revealed that the number of upregulated leucocytes, eosinophils, neutrophils and lymphocytes, induced by OVA induction, was markedly reduced by the
TLR4-shRNA treatment. Emerging evidence has demonstrated that inflammatory mechanisms serve an important role in AR development (45). Further analysis indicates that the serum levels of IL-4, IL-5, IL-13, IL-17 and TNF- $\alpha$, which are major mediators produced by Th 2 cells, were reduced following TLR4-shRNA treatment. Levels of IFN- $\gamma$ and IL-2, which are primarily produced by Th1 cells, were upregulated by TLR4-shRNA. TLR4-shRNA may therefore exhibit a therapeutic effect on AR mice by downregulating pro-inflammatory cytokines produced by $\mathrm{Th} 2$ cells. As the major transmembrane receptor for allergens, TLR4 transcribes $\mathrm{NF}-\kappa \mathrm{B}$ in the nucleus through a series of complex intracellular signal transduction pathways mediated by the adaptor protein myeloid differentiation primary response protein-88, thereby inducing the release of a large number of inflammatory factors including TNF- $\alpha$, IL-1 and IL-6, which in turn mediate and aggravate airway inflammation (46). The current study also elucidated as to whether NF- $\mathrm{BB}$ pathway was involved in the effects of TLR4 on AR mice and the data indicated that OVA-induced activation of the NF- $\mathrm{kB}$ pathway was inhibited by TLR4-shRNA administration.

In summary, the expression of TLR4 was upregulated in the OVA-induced AR mouse model. Administration of TLR4-shRNA alleviated the allergic symptoms of AR mice by regulating the production of pro-inflammatory mediators. The present study revealed that TLR4-shRNA may effectively alleviate allergic symptoms in AR mice and is therefore a promising therapeutic agent for AR treatment. The current study is, however, preliminary and has limitations. The NF- $\kappa B$ inhibitor should be used to confirm the effect of TLR4-shRNA on the NF- $\kappa B$ pathway. Percentages of the different cell types (leucocytes, eosinophils, neutrophils and lymphocytes) were not analyzed in this study. In addition, the relevant TLR4 ligand(s) in OVA-induced AR, whether LPS presented in the environment or possibly in the OVA and whether OVA was endotoxin-free were also not determined in the current study. These issues should be further investigated to fully elucidate the role of TLR4 in AR development.

\section{Acknowledgements}

Not applicable.

\section{Funding}

The present study was supported by Taizhou Science and Technology Department Foundation of Zhejiang Province (grant no. 2016A33631).

\section{Availability of data and materials}

The analyzed data sets generated during the present study are available from the corresponding author on reasonable request.

\section{Authors' contributions}

HX designed the current study, collected and analyzed the data, performed statistical analysis, searched the literature, and prepared the manuscript. HS, JZ and JS collected the data, performed the statistical analyses and interpreted the data. 


\section{Ethics approval and consent to participate}

All animal experiments were performed in accordance with the protocol approved by the Care and Use of Laboratory Animals Committee. The current study was approved by the Committee on the Use and Care of Animals of Taizhou Central Hospital (Taizhou University Hospital, Taizhou, China).

\section{Patient consent for publication}

Not applicable.

\section{Competing interests}

The authors declare that they have no competing interests.

\section{References}

1. Bousquet J, Khaltaev N, Cruz A A Denburg J,Fokkens WJ,Togias A,ZuberbierT,Baena-CagnaniCE, Canonica GW, van Weel C, et al: Allergic Rhinitis and its Impact on Asthma (ARIA) 2008 update (in collaboration with the World Health Organization, GA(2)LEN and AllerGen). Allergy 63: 8-160, 2008 .

2. Wang Y, Lin L and Zheng C: Downregulation of Orai1 expression in the airway alleviates murine allergic rhinitis. Exp Mo Med 44: 177-190, 2012.

3. Rosati MG and Peters AT: Relationships among allergic rhinitis, asthma and chronic rhinosinusitis. Am J Rhinol Allergy 30: 44-47, 2016.

4. Settipane RA and Schwindt C: Chapter 15: Allergic rhinitis. Am J Rhinol Allergy 27 (Suppl 1): S52-S55, 2013.

5. Sur DK and Plesa ML: Treatment of allergic rhinitis. Am Fam Physician 92: 985-992, 2015.

6. Bernstein DI, Schwartz G and Bernstein JA: Allergic rhinitis: Mechanisms and treatment. Immunol Allergy Clin North Am 36 : 261-278, 2016.

7. Andersson M, Greiff L, Ojeda P and Wollmer P: Barrier-enforcing measures as treatment principle in allergic rhinitis: A systematic review. Curr Med Res Opin 30: 1131-1137, 2014.

8. Steelant B, Farré R, Wawrzyniak P, Belmans J, Dekimpe E, Vanheel H, Van Gerven L, Kortekaas Krohn I, Bullens DMA, Ceuppens JL, et al: Impaired barrier function inpatients with house dust mite-induced allergic rhinitis is accompanied bydecreased occludin and zonula occludens-1 expression. J. Allergy Clin.Immunol 137: 1043-1053, 2016.

9. Wang DY: Risk factors of allergic rhinitis: Genetic or environmental? Ther Clin Risk Manag 1: 115-123, 2005.

10. Ciprandi G, Marseglia GL, Castagnoli R, Valsecchi C Tagliacarne C, Caimmi S and Licari A: From IgE to clinical trials of allergic rhinitis. Expert Rev Clin Immunol 11: 1321-1333, 2015.

11. Hashimoto C Hudson KL and Anderson KV: The toll gene of Drosophila, required for dorsal-ventral embryonic polarity, appears to encode a transmembrane protein. Cell 52: 269-279, 1988.

12. Lemaitre B Nicolas E, Michaut L, Reichhart JM and Hoffmann JA: The dorsoventral regulatory gene cassette spätzle/Toll/cactus controls the potent antifungal response in Drosophila adults. Cell 86: 973-983, 1996.

13. Medzhitov R, Preston-Hurlburt P and Janeway CA Jr: A human homologue of the Drosophila Toll protein signals activation of adaptive immunity. Nature 388: 394-397, 1997.

14. Iwasaki A and Medzhitov R: Regulation of adaptive immunity by the immune system. Science 327: 291-295, 2010.

15. Akira $\mathrm{S}$ and Takeda K: Toll-like receptor signalling. Nat Rev Immunol 4: 499-511, 2004.

16. Takeda K, Kaisho T and Akira S: Toll-like receptors. Annu Rev Immuno1 21: 335-376, 2003.

17. Molteni M, Gemma S and Rossetti C: The role of toll-like receptor 4 in infectious and noninfectious inflammation. Mediators Inflamm 2016: 6978936, 2016.

18. Beutler B: TLR4 as the mammalian endotoxin sensor. Curr Top Microbiol Immunol 270: 109-120, 2002.
19. Beutler B, Du X and Poltorak A: Identification of toll-like receptor 4 (TLR4) as the sole conduit for LPS signal transduction: Genetic and evolutionary studies. J Endotoxin Res 7: 277-280, 2001.

20. Garibotto G, Carta A, Picciotto D, Viazzi F and Verzola D: Toll-like receptor-4 signaling mediates inflammation and tissue injury in diabetic nephropathy. J Nephrol 30: 719-727, 2017.

21. Maglione PJ, Simchoni N and Cunningham-Rundles C: Toll-like receptor signaling in primary immune deficiencies. Ann N Y Acad Sci 1356: 1-21, 2015.

22. Dong L, Li H, Wang S and Li Y: Different doses of lipopolysaccharides regulate the lung inflammation of asthmatic mice via TLR4 pathway in alveolar macrophages. J Asthma 46: 229-233, 2009.

23. Peters M, Dudziak K, Stiehm M and Bufe A: T-cell polarization depends on concentration of the danger signal used to activate dendritic cells. Immunol Cell Biol 88: 537-544, 2010.

24. Takabayashi K, Libet L, Chisholm D, Zubeldia J and Horner AA: Intranasal immunothcrapy is more effective than intradcrmal immunotherapy for the induction of air-way allergen tolerance in Th2-sensitized mice. J Immunol 170: 3898-3905, 2003.

25. Cui XY, Chen X, Yu CJ, Yang J, Lin ZP, Yin M and Cheng L: Increased expression of toll-like receptors 2 and 4 and related cytokines in persistent allergic rhinitis. Otolaryngol Head Neck Surg 152: 233-238, 2015.

26. Xiao L, Jiang L, Hu Q and Li Y: MicroRNA-133b ameliorates allergic inflammation and symptom in murine model of allergic rhinitis by targeting Nlrp3. Cell Physiol Biochem 42: 901-912, 2017.

27. Yuan Y, Liu Q, Zhao J, Tang H and Sun J: SIRT1 attenuates murine allergic rhinitis by downregulated HMGB 1/TLR4 pathway. Scand J Immunol 87: e12667, 2018.

28. Livak KJ and Schmittgen TD: Analysis of relative gene expression data using real-time quantitative PCR and the 2(-Delta Delta C(T)) method. Methods 25: 402-408, 2001.

29. Casale TB and Dykewicz MS: Clinical implications of the allergic rhinitis-asthma link. Am J Med Sci 327: 127-138, 2014.

30. Brożek JL, Bousquet J, Agache I, Agarwal A, Bachert C, Bosnic-Anticevich S, Brignardello-Petersen R, Canonica GW, Casale T, Chavannes NH, et al: Allergic Rhinitis and its Impact on Asthma (ARIA) guidelines:evision. J Allergy Clin Immunol 140: 950-958, 2017.

31. Izquierdo-Domínguez A, Valero AL and Mullol J: Comparative analysis of allergic rhinitis in children and adults. Curr Allergy Asthma Rep 13: 142-151, 2013.

32. Shimazu R, Akashi S, Ogata H, Nagai Y, Fukudome K, Miyake K and Kimoto M: MD-2, a molecule that confers lipopolysaccharide responsiveness on Toll-like receptor 4. J Exp Med 189: 1777-1782, 1999.

33. Rifkin IR, Leadbetter EA, Busconi L, Viglianti G and Marshak-Rothstein A: Toll-like receptors, endogenous ligands and systemic autoimmune disease. Immunol Rev 204: 27-42, 2005.

34. Kang JY and Lee JO: Structural biology of the Toll-like receptor family. Annu Rev Biochem 80: 917-941, 2011.

35. Peri F and Calabrese V: Toll-like receptor 4 (TLR4) modulation by synthetic and natural compounds an update. J Med Chem 57: 3612-3622, 2014.

36. Zhong JJ, Wan YY, Diao YW, et al: The research development of Toll-like receptors targeted drugs. Chin Bull Life Dci 27: 439-444, 2015 (In Chinese).

37. Sasai $\mathrm{M}$ and Yamamoto $\mathrm{M}$ : Pathogen recognition receptors: Ligands and signaling pathways by Toll-like receptors. Int Rev Immunol 32: 116-133, 2013.

38. Fuertes E, Brauer M, MacIntyre E, Bauer M, Bellander T, von Berg A, Berdel D, Brunekreef B, Chan-Yeung M, Gehring U, et al: Childhood allergic rhinitis, traffic-related air pollution and variability in the GSTP1, TNF, TLR2 and TLR4 genes: Results from the TAG study. J Allergy Clin Immunol 132: 342-352.e2, 2013.

39. Radman M, Golshiri A, Shamsizadeh A, Zainodini N, Bagheri V, Arababadi MK and Kennedy D: Toll-like receptor 4 plays significant roles during allergic rhinitis. Allergol Immunopathol (Madr) 43: 416-420, 2015.

40. Zhong H, Fan XL, Yu QN, Qin ZL, Chen D, Xu R, Chen DH, Lin ZB, Wen W and Fu QL: Increased innate type 2 immune response in house dust mite-allergic patients with allergicrhinitis. Clin Immunol 183: 293-299, 2017.

41. Madore AM and Laprise C: Immunological and genetic aspects of asthma and allergy. J Asthma Allergy 3: 107-121, 2010.

42. Galli SJ and Tsai M: IgE and mast cells in allergic disease. Nat Med 18: 693-704, 2012. 
43. Metcalfe DD, Pawankar R, Ackerman SJ, Akin C, Clayton F, Falcone FH, Gleich GJ, Irani AM, Johansson MW, Klion AD, et al Biomarkers of the involvement of mast cells, basophils and eosinophils in asthma and allergic diseases. World Allergy Organ J 9: 7, 2016.

44. FujitaniY,KanaokaY,AritakeK,UodomeN,Okazaki-HatakeKand Urade Y: Pronounced eosinophilic lung inflammation and Th2 cytokine release in human lipocalin-type prostaglandin D synthase transgenic mice. J Immunol 168: 443-449, 2002.
45. Bae JS, Kim JH, Kim EH and Mo JH: The role of IL-17 in a lipopolysaccharide-induced rhinitis model. Allergy Asthma Immunol Res 9: 169-176, 2017.

46. Eswarappa SM, Basu N, Joy O and Chakravortty D: Folimycin (concanamycin A) inhibits LPS-induced nitric oxide production and reduces surface localization of TLR4 in murine macrophages. Innate Immun 14: 13-24, 2008. 